\title{
PENJUALAN ONLINE BERBASIS E-COMMERCE PADA TOKO ADHIZZSHOP DENGAN MENGGUNAKAN WOOCOMMERCE
}

\author{
Syuhendra $^{1)}$, Agus Umar Hamdani ${ }^{2)}$ \\ ${ }^{1}$ Sistem Informasi, Fakultas Teknologi Informasi, Universitas Budi Luhur \\ ${ }^{1,2} \mathrm{Jl}$. Raya Ciledug, Petukangan Utara, Kebayoran Lama, Jakarta Selatan 12260 \\ E-mail : 1512502046@student.budiluhur.ac.id ${ }^{1)}$, agus.umarhamdani@budiluhur.ac.id ${ }^{2)}$
}

\begin{abstract}
Abstrak
Adhizzshop merupakan sebuah badan usaha perorangan yang bergerak dalam bidang penjualan pakaian untuk anak-anak. Dalam mengembangkan penjualan selain menjual produk secara offline juga menjual produk secara online. Proses bisnis yang ada terjadi pada toko ini yaitu pelanggan dapat datang langsung ke toko adhizzshop atau pelanggan bisa melakukukan pemesanan melalui whatsapp dan facebook. Kendala yang terjadi pada Adhizzshop kurang maksimalnya pemasaran produk yang dijual dan tidak adanya pembuatan laporan penjualan serta masalah dalam pengolahan data. Berdasarkan permasalahan yang ada pada adhizzshop peneliti melakukan perancangan dalam pembuatan sebuah website E-Commerce untuk memudahkan proses penjualan secara online. Metodologi yang digunakan dalam penelitian ini menggunakan pendekatan penelitian terapan (Applied Research). Dalam mengumpulkan data, penulis menggunakan metode wawancara, observasi, analisa dokumen dan studi literatur. Analisis dan perancangan sistem E-Commerce menggunakan metodologi berorientasi obyek serta implementasi sistem E-Commerce menggunakan Content Management System (CMS) wordpress dengan plugin woocommerce. Penelitian ini menghasilkan aplikasi E-Commerce yang dapat menunjang penjualan dan pengolahan data penjualan serta transaksi yang ada pada Toko Adhizzshop.
\end{abstract}

Kata kunci: E-Commerce, Pakaian anak-anak, Content Management System.

\section{PENDAHULUAN}

Perkembangan dan kemajuan bisnis tidak luput dari adanya teknologi informasi, dengan kemajuan teknologi informasi yang sangat pesat dapat memberikan kemudahan dalam mencari suatu informasi sesuai apa yang di inginkan. Teknologi informasi sangat dibutuhkan oleh sebuah instansi atau perusahaan untuk menunjang efesiensi dan efektifitas dalam mengelola data agar didapatnya informasi yang dibutuhkan. Dalam dunia bisnis marak dengan munculnya suatu istilah Electronic Commerce (E-Commerce). Menurut Shabur Miftah Maulana, dan Heru Susilo, Riyadi [1], E-Commerce adalah suatu proses membeli dan menjual produk produk secara elektronik oleh konsumen dan dari perusahaan ke perusahaan dengan komputer sebagai perantara transaksi bisnis. Media yang dapat digunakan dalam aktivitas e-commerce adalah world wide web internet. Dalam mengembangkan sebuah usaha para pemilik usaha ingin produk yang mereka miliki dijangkau oleh banyak konsumen. Adhizzshop merupakan sebuah badan usaha perorangan yang bergerak dibidang penjualan pakaian untuk anak-anak. Dalam mengembangkan usaha ini pemilik Adhizzshop selain menjual produk secara offline, juga dipasarkan online melalui media sosial. Proses bisnis yang berjalan saat ini mengalami kendala dalam masalah pembuatan laporan dan pengolahan data sehingga tidak adanya laporan penjualan serta pemasaran yang kurang maksimal. Berdasarkan hal tersebut, perlu dibuatkan sebuah website E-Commerce yang dapat memudahkan dalam pengolahan data dan membantu memasarkan produk dengan jangkauan yang lebih luas serta membantu aktivitas pengolahan data dan meningkatkan pendapatan penjualan pada Toko Adhizzshop. Peneliti melakukan peninjauan terhadap studi mengenai E-Commerce yang telah dilakukan oleh beberapa peneliti sebelumnya sebagai berikut: "Sistem Penjualan Berbasis Web (ECommerce) Pada Tata Distro Kabupaten Pacitan” [2]. Permasalahan yang dibahas antara lain : terjadi kesalahan pada pencatatan dan pencarian data yang sulit karena setiap dilakukan mencari data penjual harus mencari pada buku besar. Tidak ada informasi khusus yang menginformasikan tentang jumlah stok. Penelitian berikutnya berjudul "Perancangan Aplikasi E-Commerce Pada Toko I'M Collection WTC Jambi” [3]. Sistem pemasaran dan penjualan pada toko I'm Collection sekarang ini pembeli harus datang langsung ke toko untuk melihat dan membeli barang. Metode penelitian yang digunakan adalah metode penelitian lapangan serta wawancara. Penelitian ini menghasilkan sebuah aplikasi yang terkomputerisasi dengan menggunakan bahasa pemograman utama PHP dan Database MySQL. Penelitian berikutnya berjudul "Perancangan Sistem Informasi Penjualan Berbasis E-Commerce Studi Kasus Toko Kun Jakarta” [4]. Permasalahan yang diangkat antara lain: media promosi hanya menggunakan spanduk, penjualan masih sebatas offline, penyimpanan data dan pencetakan laporan 
masih berupa pencatatan dalam bentuk arsip. Metode penelitian ini menggunakan metode waterfall. Penelitian ini menghasilkan aplikasi penjualan berbasis E-Commerce untuk meningkatkan penjualan baju muslim pada toko KUN Jakarta. Penelitian berikutnya berjudul "Model E-Commerce Dengan Metode Web Engineering Method Untuk Menunjang Pemasaran Produk pada XYZ Pet Shop" yang membahas pembuatan prototipe E-Commerce guna menunjang aktivitas penjualan dan pemasaran produk makan hewan peliharaan pada XYZ Pet Shop [5]. Masalah yang dihadapi toko Adhizzshop adalah produk ter-upload secara acak pada halaman facebook, ketersediaan stok tidak diketahui customer, tidak adanya laporan penjualan, promosi kurang efektif, dan customer tidak mengetahui status pengiriman pesanan. Adapun tujuan penelitian ini untuk membuat model sistem E-Commerce untuk menunjang penjualan pakaian anak pada toko Adhizzshop. Berdasarkan kondisi diatas, maka rumusan masalah yang harus dijawab adalah bagaimana menganalisa dan membuat aplikasi E-Commerce guna memaksimalkan pemasaran pada toko Adhizzshop. Tujuan penelitian ini adalah membangun aplikasi $E$ Commerce untuk mendukung pemasaran pada toko Adhizzshop.

\section{METODE PENELITIAN}

\subsection{Langkah-Langkah Penelitian}

Dalam penelitian ini diperlukan tahapan penelitian yang merupakan langkah-langkah yang harus dikerjakan dalam suatu penelitian, dimana langkah-langkah tersebut merupakan petunjuk untuk melakukan kegiatan penelitian secara sistematis. Adapun langkah-langkah penelitian dijelaskan pada gambar 1 berikut ini :

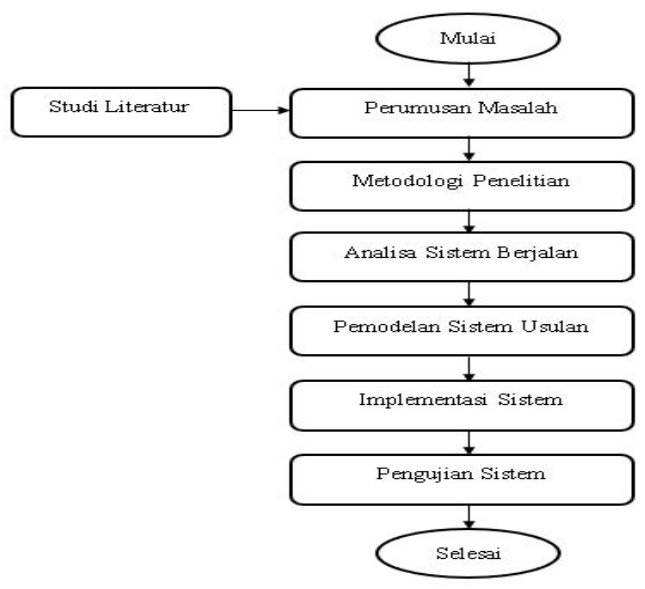

Gambar 1. Langkah-Langkah Penelitian

\subsection{Metode Pengembangan Sistem}

Dalam penelitian ini menggunakan metode pengembang sistem dengan metode Waterfall Development. Penentuan metode pengembangan sistem berdasarkan kesesuaian model untuk dipakai, dalam metode Waterfall setiap tahapan-tahapan saling memiliki keterkaitan dan pengaruh.

\subsection{Metode Pengumpulan Data}

Dalam menyelesaikan penelitian dibutuhkan data yang berhubungan dengan topik yang dibahas. Metode yang digunakan dalam teknik pengumpulan data pada penelitian ini adalah sebagai berikut:

a. Wawancara

Untuk mengetahui masalah-masalah yang terjadi yang terjadi pada Adhizzshop maka dilakukan wawancara dengan mengajukan beberapa pertanyaan lisan dengan pemilik toko.

\section{b. Observasi}

Peneliti melakukan riset langsung ke lokasi usaha untuk mengumpulkan data dan mengamati proses bisnis yang terjadi pada Adhizzshop yang bertujuan untuk mengetahui informasi secara detil dalam merancang sistem yang akan diterapkan pada Adhizzshop.

c. Analisa Dokumen

Peneliti mengumpulkan dokumen proses bisnis berjalan pada Adhizzshop yang bertujuan untuk memperoleh informasi yang berguna untuk kebutuhan sistem.

\section{d. Studi Literatur}

Sedangkan studi literatur untuk pengumpulan data melalui buku di perpustakaan maupun e-book serta dari beberapa jurnal dari penelitian sebelumnya yang nantinya akan dijadikan sebagai acuan kegiatan penelitian.

\subsection{Teknik Analisa Data}

Berikut ini adalah teknik analisa dapat yang dilakukan :

a. Analisa Model Bisnis Kanvas

Analisa model bisnis kanvas atau BMC (Business Model Canvas) digunakan untuk mendeskripsikan dan merancang model bisnis pada Adhizzshop. Business Model Canvas (BMC) dapat menjelaskan hubungan sembilan elemen model bisnis yang digambarkan secara visual, sehingga inovasi yang dibuat pada model bisnis perusahaan akan lebih mudah dipahami dan dimengerti.

b. Analisa Proses Bisnis

Analisa proses bisnis berisi penguraian tentang proses bisnis berjalan Adhizzshop yang kemudian digambarkan pada Activity Diagram menggunakan Microsoft Visio.

c. Analisa Masalah

Dalam menganalisa masalah, peneliti menguraikan sebab akibat dari permasalahan yang 
ada pada Adhizzshop.

d. Analisa Kebutuhan Sistem

Setelah mengetahui permasalahan yang terjadi pada Adhizzshop, peneliti melakukan analisa kebutuhan sistem dan membuatkan solusi dengan mengidentifikasi kebutuhan fungsional serta non fungsional. Lalu digambarkan pada Use Case Diagram menggunakan Microsoft Visio.

\subsection{Teknik Search Engine Optimization (SEO)}

Adapun teknik Search Engine Optimization (SEO) yang dilakukan antara lain :
a. Permalink, dengan mengatur URL yang lebih mendukung SEO.
b. Yoast SEO digunakan untuk pengelolaan SEO pada website.
c. Google Webmaster, dengan memverifikasi website agar ter-index pada google.
d. Title Tag, bertujuan untuk memudahkan dalam mengtahui konten website secara singkat.
e. Meta Description, digunakan untuk mendeskripsikan isi konten website.
f. Focus Keyword, dengan mengatur kata kunci yang tepat untuk memudahkan bersaing pada halaman mesin pencari.
g. Alt Text, memudahkan mesin pencari memahami sebuah gambar.

\section{HASIL DAN PEMBAHASAN}

\subsection{Business Model Canvas}

Berikut ini adalah Business Model Canvas pada penjualan online pada Adhizzshop yang dijelaskan pada gambar 2 berikut ini :

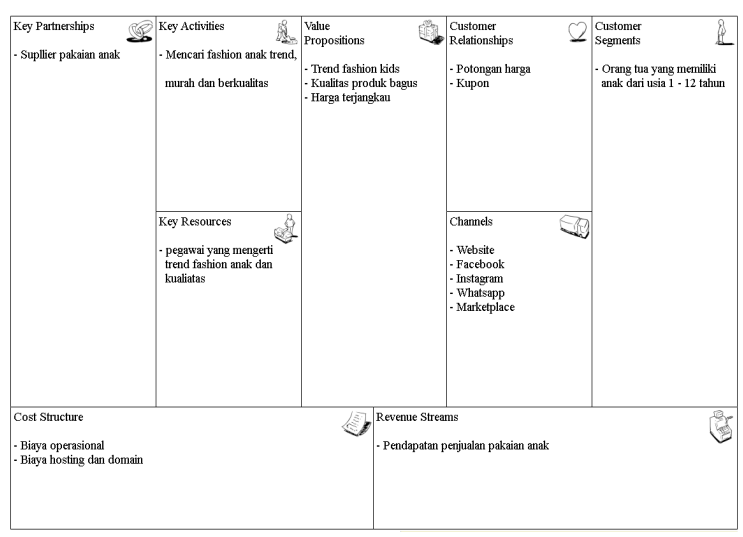

Gambar 2. Business Model Canvas

Pada gambar 2 merupakan penguraian tentang business model canvas:

a. Value Propositions, nilai dan manfaat yang ingin diberikan kepada calon customer adalah produk yang ditawarkan merupakan produk yang trend untuk anak-anak dan berkualitas baik dengan harga yang terjangkau.

b. Customer Segments, perusahan ini menargetkan pemasaran kepada orang tua yang memiliki anak 1 tahun hingga 12 tahun.

c. Customer Relationships, cara perusahan dalam menjalin hubungan dengan calon customer adalah dengan mengadakan potongan harga dan kupon.

d. Channels yang diterapkan adalah marketplace dan website serta media sosial yaitu facebook, instagram, dan whatsapp sebagai sarana untuk menyampaikan value proposition kepada pelanggan.

e. Key Activities yang dilakukan yaitu mencari pakain anak yang trend dan berkualitas serta murah.

f. Key Resources, sumber daya yang diperlukan supaya bisnis perusahan berjalan dengan baik adalah dengan memiliki pegawai yang mengerti trend fashion anak dan berkualitas.

g. Key Partnerships yaitu sebagai mitra kerja dalam menujang bisnis adalah supllier pakaian anak untuk pembelian produk yang akan dijual.

h. Cost Structure, struktur biaya untuk menjalankan perusahaan adalah biaya operasional yang pasti dikeluarkan per bulan dan hosting \& domain yang pasti dikeluarkan per tahun.

i. Revenue Streams, sumber pendapatan bisnis dalam perusahan ini adalah pendapatan yang dihasilankan dari penjulan produk yang ada pada Adhizzshop.

\subsection{Activity Diagram Pemesanan}

Customer memilih produk yang diingikan kemudian memasukan ke dalam cart. Kemudian customer klik checkout, jika sudah dalam keadaan login sistem akan menampilkan form pemesanan. Customer mengisi form pemesanan dan memilih kurir yang akan digunakan setelah itu sistem akan menampilkan total harga pesanan. Kemudian customer memilih metode pembayaran yang akan digunakan. Ketika pemesanan berhasil,sistem menyimpan data dan customer serta admin akan mendapatkan email notifikasi bukti pemesanan dari sistem yang berisi produk yang dipesan dan jumlah yang harus dibayarkan. Activity diagram pemesanan dapat dilihat pada gambar 3 berikut ini : 


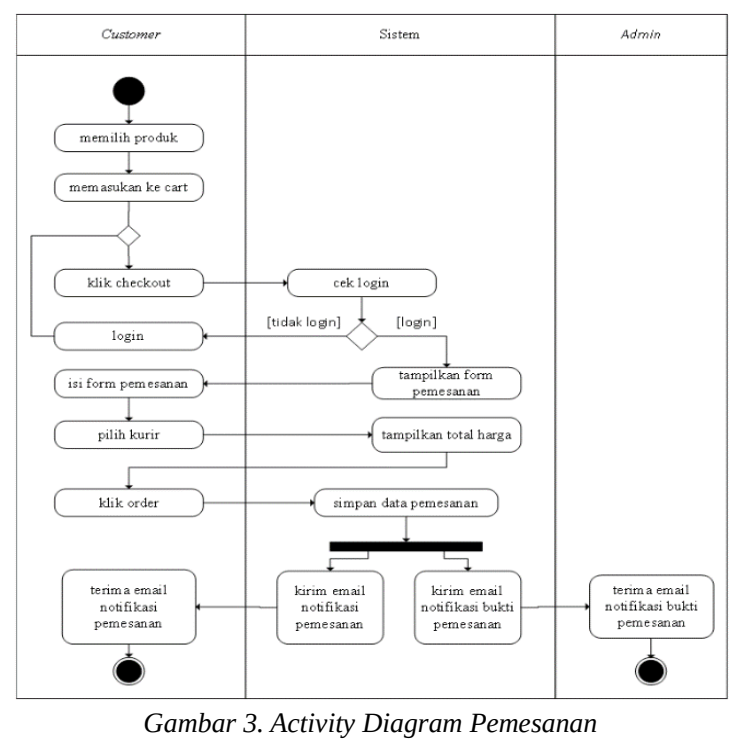

\subsection{Use Case Diagram}

Use case diagram digambarkan berdasarkan proses bisnis usulan , sebagai berikut:

a. Use Case Diagram Login

Pada gambar 4 merupakan use case diagram login yang terdiri dari actor user dan use case login dan logout.

Gambar 4. Use Case Diagram Login

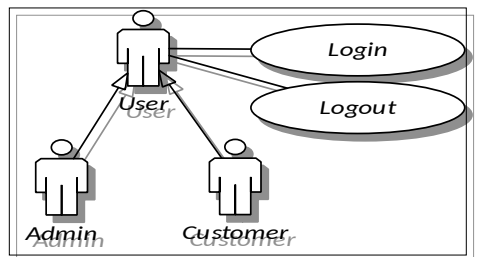

b. Use Case Diagram Master

Pada gambar 5 merupakan use case diagram master yang terdiri dari actor admin, system, dan customer. Terdapat use case entry produk, kategori, attribute, entry register dan system menjalankan notifikasi email register.
Gambar 5. Use Case Diagram Master

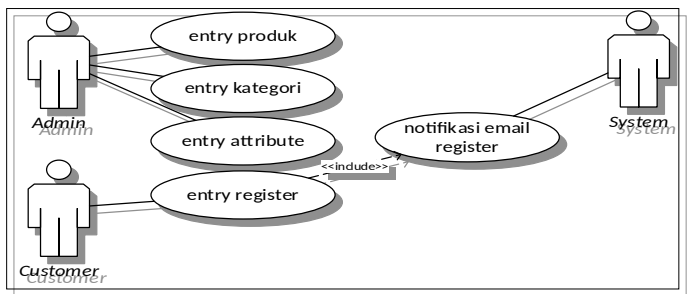

c. Use Case Diagram Transaksi

Pada gambar 6 merupakan merupakan use case diagram transaksi yang terdiri actor customer, admin, dan system. Terdapat use case entry pemesanan, entry konfirmasi bayar, konfirmasi penerimaan, verifikasi pembayaran, entry pengiriman, entry promosi serta actor system menjalakan use case notifikasi email pemesanan, notifikasi email konfirmasi bayar, notifikasi email verifikasi pembayaran, notifikasi email pengiriman, notifikasi email promosi.

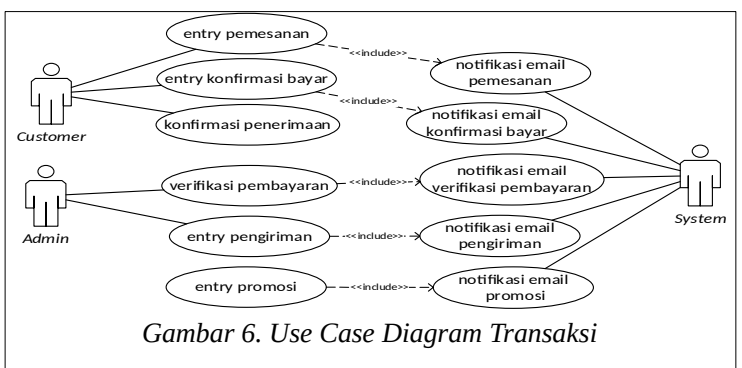

d. Use Case Diagram Laporan

Pada gambar 7 merupakan use case diagram laporan yang terdiri dari actor admin dan pemilik yang terdapat use case cetak laporan penjualan, cetak laporan pembayaran, cetak laporan pengiriman, cetak laporan produk terlaris, cetak laporan promosi dan cetak laporan pemesanan.

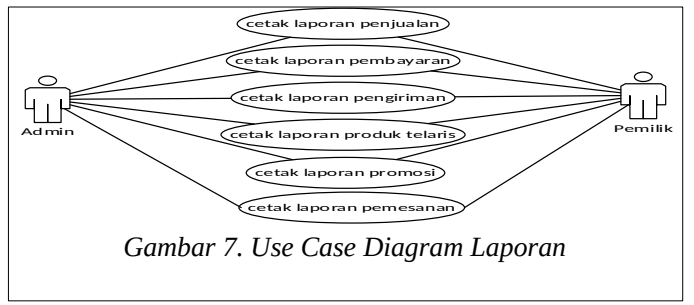

\subsection{Class Diagram}

Model basis data untuk sistem penjualan online pada website Adhizzshop dijelaskan pada gambar 8 sebagai berikut: 
Gambar 8. Class Diagram

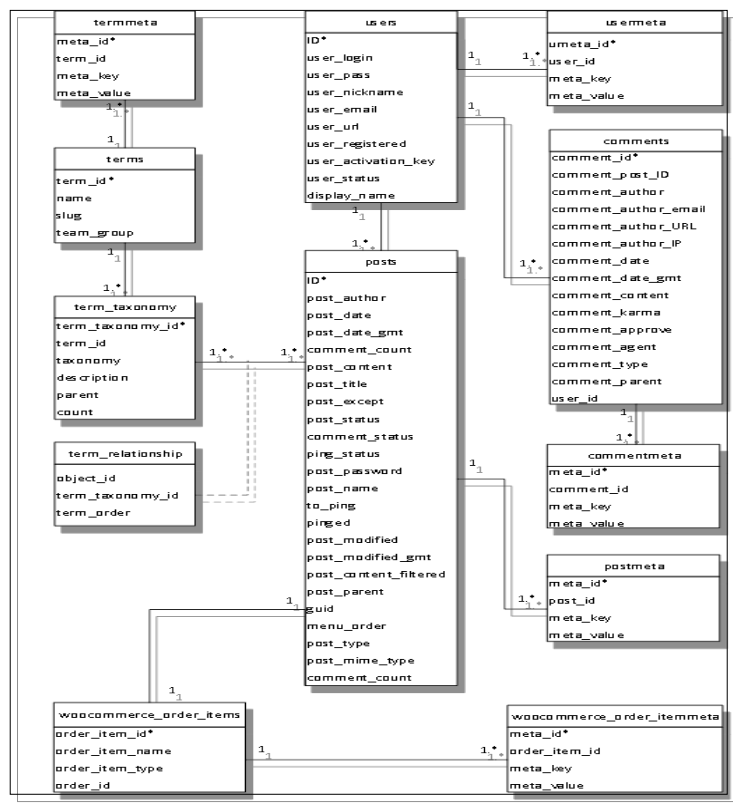

3.5. System Sequance Diagram Entry Pemesanan

Pada gambar 9 merupakan system sequance diagram entry pemesanan dimulai dari customer memberikan action membuka menu shop sistem akan merespon dengan menampilkan produk-produk kemudian cutomer memilih produk dan add to cart terdapat loop dimana customer dapat memilih produk dan add to cart secara berkali-kali. Kemudian customer membuka menu cart sistem menampilkan menu cart, terdapat fragment optional customer dapat memberikan action menambah jumlah produk, input coupon code dan delete atau tidak memberikan action tersebut terhadap sistem. Lalu customer proceed to checkout sistem menampilkan form checkout, customer input data checkuot kemudian place order sistem akan

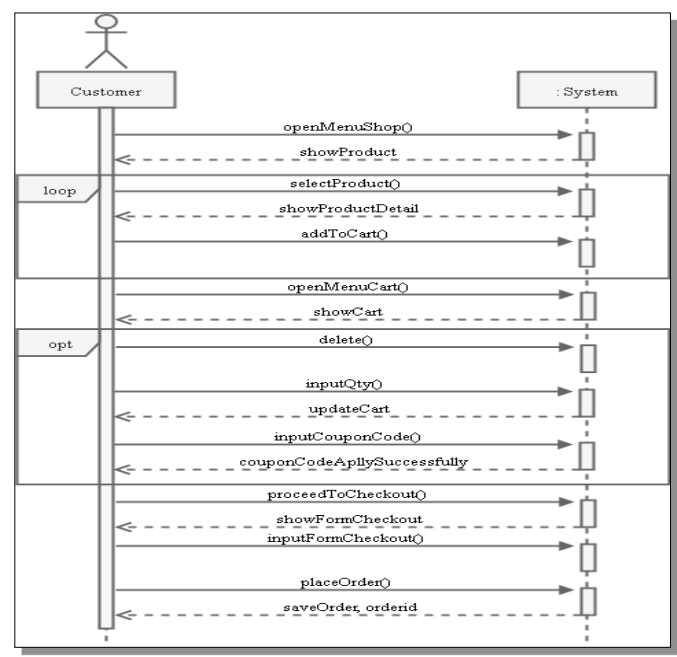

menyimpan data dan menampilkan order id.

Gambar 9. System Sequance Diagram Entry Pemesanan

\subsection{Implementasi Sistem}

a. Tampilan Halaman Home

Tampilan home pada website Adhizzshop dapat dilihat pada gambar 10 berikut ini: 


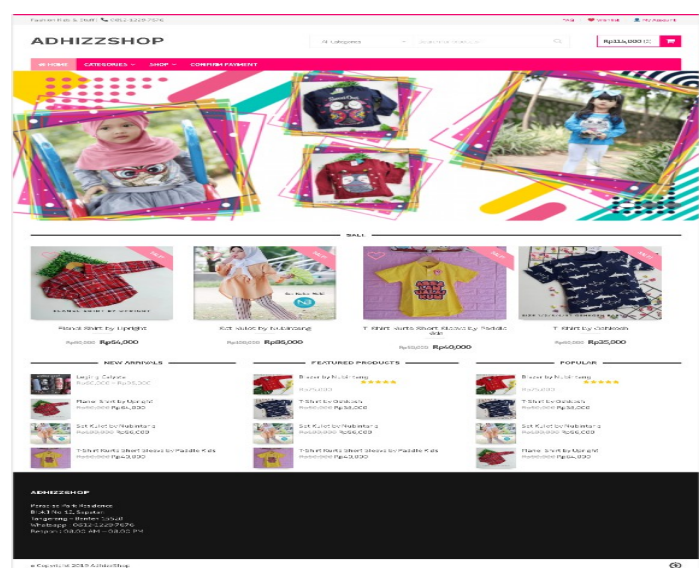

Gambar 10. Tampilan Halaman Home

b. Tampilan Halaman Shop

Tampilan halaman shop pada website Adhizzshop dapat dilihat pada gambar 11 berikut ini:

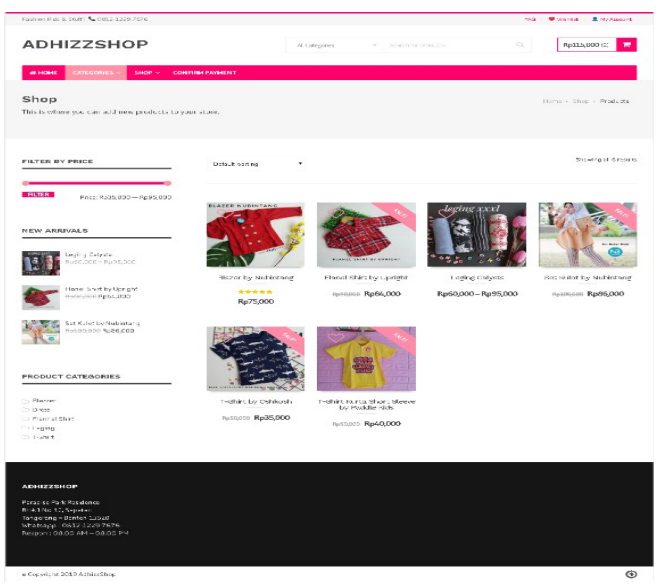

Gambar 11. Tampilan Halaman Shop

c. Tampilan Halaman Cart

Tampilan halaman cart pada website Adhizzshop dapat dilihat pada gambar 12 berikut ini:

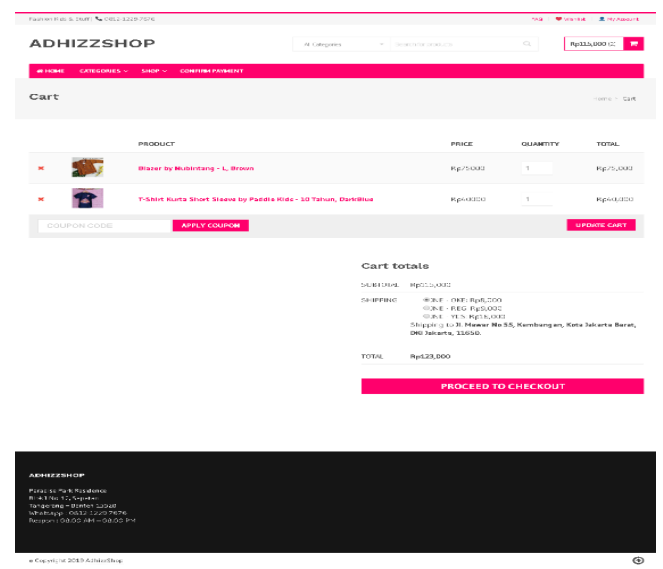

Gambar 12. Tampilan Halaman Cart

d. Tampilan Halaman Checkout

Tampilan halaman checkout pada website Adhizzshop dapat dilihat pada gambar 13 berikut ini:

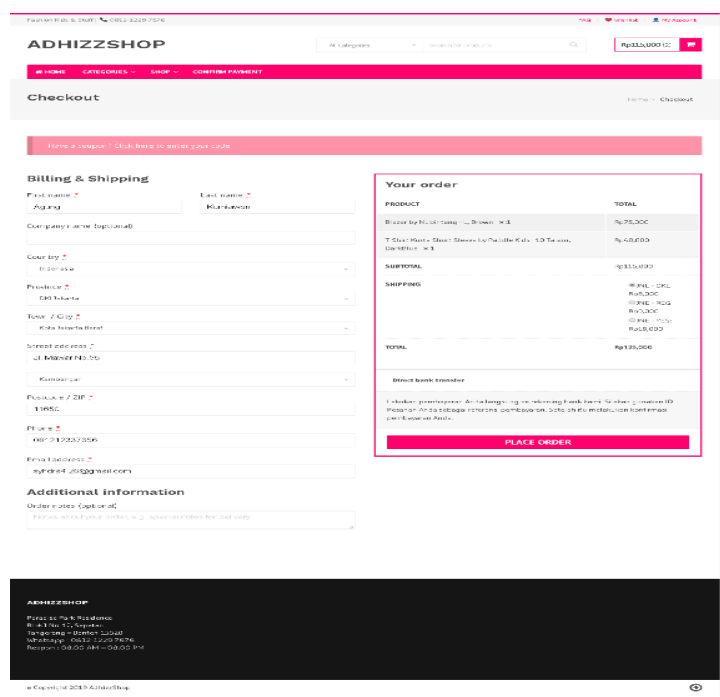

Gambar 13. Tampilan Halaman Checkout

e. Tampilan Laporan Penjualan

Tampilan laporan penjualan pada website Adhizzshop dapat dilihat pada gambar 14 berikut ini:

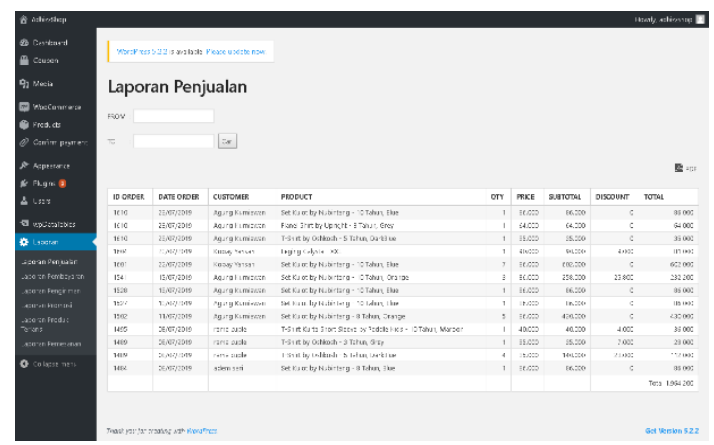

Gambar 14. Tampilan Laporan Penjualan 


\subsection{Hasil Keluaran Program} berikut:

Hasil keluaran program diantaranya sebagai

a. Laporan Penjualan

Hasil keluaran dari laporan penjualan dalam bentuk pdf dapat dilihat pada gambar 15 berikut ini:

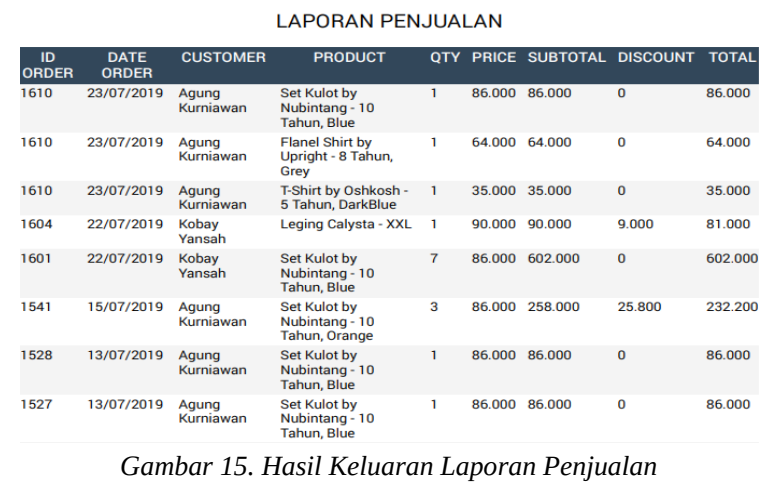

b. Email notifikasi pemesanan

Notifikasi email butki pemesanan yang didapatkan oleh admin dapat dilihat pada gambar 16 berikut ini:.

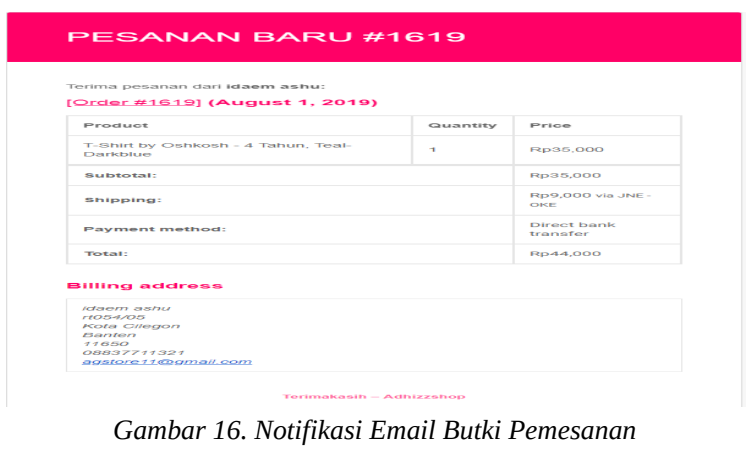

\subsection{Implementasi Search Engine Optimization} Dalam penerapan SEO (Search Engine Optimization) terdapat berapa langkah sebagai berikut :

a. Mengubah Permalink

Permalink diubah menjadi singkat dengan cara memilih menu setting pada halaman dashboard admin kemudian klik permalink dan pilih post name pada common setting. Pada product permalink pilih shop base kemudian save.

b. Install Plugin Yoast SEO

Untuk lebih mudah dalam pengoptimalan SEO, install plugin Yoast SEO dengan cara pilih plugin lalu add new plugin, search plugin Yoast SEO lalu klik install kemudian activate.

c. Verifikasi Google Websmaster

Pada tahap ini digunakan untuk memudahkan website ter-index pada halaman pencarian google dengan cara mendaftarkan website pada account google webmaster kemudian meletakan kode verifikasi pada website dan kemudian verify pada google webmaster.

d. Title Tag

Title tag merupakan HTML tag yang memberikan judul pada halaman website. Title tag akan muncul pada hasil pencarian, oleh karena itu judul harus sesuai dengan isi content. Dengan plugin yoast seo lebih memudahkan dalam menerapkan title tag dengan cara memasukan judul pada kolom SEO Title hingga indikator berwarna hijau.

e. Meta Description

Meta description ialah atribut HTML yang berisi ringkasan halaman yang akan muncul pada hasil pencarian dibawah URL. Meta description akan memberikan informasi kepada spider atau bot tentang isi content website. Dengan plugin yoast seo lebih mudah dalam menerapkan meta description dengan cara memasukan deskripsi singkat yang terdapat kata kunci pada kolom meta description hingga indikator berwarna hijau.

f. Keyphrase

Keyphrase merupakan salah satu faktor pertimbangan mesin pencari dalam menentukan page rank. Dengan cara memasukan kata kunci yang terdiri dari 4 kata pada kolom keyphrase.

g. Alt Text

Alt text adalah atribut HTML yang menampilkan teks alternatif saat gambar pada website tidak dapat ditampilkan. Dengan cara menyisipkan kata kunci pada setiap alt gambar.

\subsection{Hasil Search Engine Optimization}

Setelah penerapan SEO (Search Engine Optimization) dilakukan pengujian SERP (Search Engine Result Page) pada mesin pencari Google untuk mengetahui posisi website Adhizzshop. Hasil pencarian pada Google dengan kata kunci nama produk "Blazer Nubintang” berada pada posisi ke-3. Dapat dilihat pada gambar 17 sebagai berikut ini: 


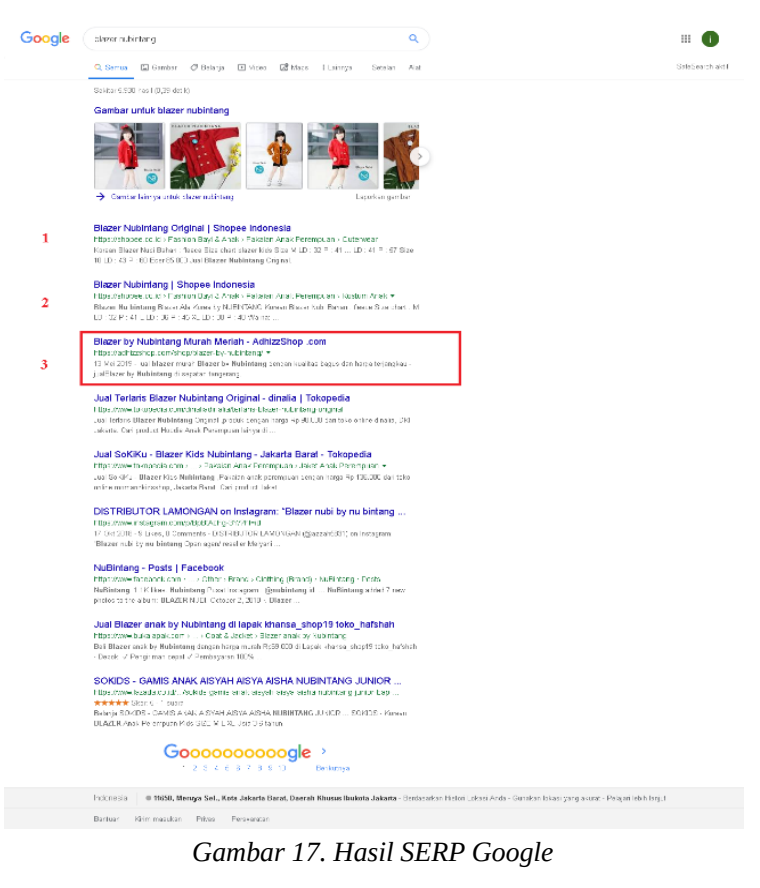

\subsection{Marketing}

Marketing yang dilakukan untuk meningkatkan penjualan pada Toko Adhizzshop adalah sebagai berikut:

a. Mengoptimalkan halaman website dengan menerpakan SEO (Search Engine Optimization) pada website Adhizzshop, agar produk yang dimiliki berada pada SERP (Search Engine Result Page) pada saat calon pelanggan melakukan penelusuran pada mesin pencari google.

b. Teknik up selling dengan mengadakan diskon dan promo menggunakan code coupon untuk mendorong calon pelanggan membelanjakan dana lebih banyak.

c. Pada halaman website pelanggan dapat berbagi mengenai produk melalui sosial media.

\section{KESIMPULAN}

Dari pembahasan yang sudah diuraikan, peneliti membuat suatu kesimpulan berdasarkan penulisan laporan penelitian ini mulai dari tahapan analisa permasalahan yang ada hingga implementasi sistem yaitu:

1. Dengan adanya fitur kategori produk lebih tertata sehingga mempermudah calon customer dalam mencari produk sesuai keinginan

2. Dengan adanya fitur stok produk maka mempermudah calon customer untuk mengetahui ketersediaan produk yang ingin dibeli.

3. Pemilik dapat mengetahui produk yang paling diminati dan mengetahui data penjualan pada Adhizzshop dengan adanya fitur laporan penjualan dan laporan produk terlaris.

4. Penerapan SEO (Search Engine Optimization) pada website Adhizzshop dapat menunjang proses promosi.

5. Dengan adanya fitur kirim resi maka mempermudah customer mengetahui status pesanan.

Untuk melengkapi apa yang telah dilakukan dalam penelitian ini dapat diberikan saran yang kiranya dapat dijadikan bahan masukan untuk pengembangan sistem selanjutnya sebagai berikut:

1. Diadakan pelatihan kepada admin dalam pengoperasian website agar informasi yang dibutuhkan tepat.

2. Melakukan back-up data secara berkala untuk mencegah hilangnya data.

3. Meningkatkan sistem pembayaran yang dapat di proses secara otomatis agar lebih mempermudah customer.

4. Untuk meningkatkan SERP (Search Engine Result Page) pada website mengadakan fitur untuk upload content yang dapat mendukung Search Engine Optimization.

5. Dilakukan proses maintenance untuk mengawasi dan meminimalisir kesalahan pada website.

\section{DAFTAR PUSTAKA}

[1] Shabur, M. M., Heru, S. dan Riyadi, 'Implementasi E-commerce Sebagai Media Penjualan Online (Studi Kasus Pada Toko Pastbrik Kota Malang)', Jurnal Administrasi Bisnis (JAB), vol. 29, pp. 1-9., 2015

[2] R. P. Hastani, B.E. Purnama, dan I. U. Wardati, "Sistem Penjualan Berbasis Web (E-Commerce) Pada Tata Distro Kabupaten Pacitan,” Indian Journal of Pure and Applied Mathematics, vol. 3, pp. 1-9, Sept. 2015.

[3] N. A. Yati, E. Fernando, dan A. Rahim, "Perancangan Aplikasi E-Commerce Pada Toko I'M Collection WTC Jambi,”Jurnal Proccesor, vol. 12, pp. 1021-1035, Oct. 2017.

[4] S. Handayani, "Perancangan Sistem Informasi Penjualan Berbasis E-Commerce Studi Kasus Toko Kun Jakarta,"ILKOM Jurnal Ilmiah, vol. 10, pp. 182-189, Aug.

[5] Hamdani, Agus Umar dan Mubarak, Rakha Luri., "Model E-Commerce Dengan Metode Web Engineering Method Untuk Menunjang Pemasaran Produk Pada XYZ Pet Shop”, Prosiding Seminar Nasional Multi Disiplin Ilmu Unisbank 2019, 
ISBN : 978-979-3649-99-3, Semarang : Universitas STIKUBANK. 